\title{
REFLEXOS DA DESIGUALDADE: A EDUCAÇÃO BRASILEIRA EM TEMPOS DE PANDEMIA
}

\author{
REFLECTIONS OF INEQUALITY: BRAZILIAN EDUCATION IN PANDEMIC TIMES
}

DOI: http://dx.doi.org/10.16891/2317-434X.v8.e3.a2020.pp605-613

Recebido em: 29.05.2020 | Aceito em: 23.08.2020

Jessica Laiane de Souza Felipe*a, Eliza Souza Silva ${ }^{a}$ Damião Gonçalves de Sousab

Centro Universitário Doutor Leão Sampaio - UNILEÃOa

Universidade Regional do Cariri - URCA ${ }^{b}$

*E-mail: jessicalaiane1212@gmail.com

\section{RESUMO}

Em tempos de pandemia, percebe-se que inúmeros são os questionamentos acerca dos rumos que o mundo irá seguir. A área da saúde, da economia, assim como na educação já está sendo impactadas. Sendo assim, o objetivo principal deste artigo é travar um discursão sobre os desafios da educação brasileira em tempos de pandemia, apresentando as marcas da desigualdade desde a sua gênese, assim como os seus impactos na atualidade brasileira. A abordagem utilizada foi a qualitativa. No que se refere a caracterização do estudo quanto aos objetivos utilizouse a pesquisa exploratória, explicativa e descritiva. No que concerne aos procedimentos aplicou-se a pesquisa bibliográfica. Constatou-se por meio deste estudo que a educação é fruto da desigualdade social, visto que está intrinsecamente relacionada ao surgimento do próprio país, que por sua vez é oriundo de um contexto eminentemente desigual. Conclui-se, portanto, que a educação brasileira possui marcas muito intensas do seu passado histórico que se refletem até os dias atuais, evidenciando o seu teor ainda segregacionista e de reforço a desigualdade. Com a pandemia do coronavírus este caráter se mostra ainda mais visível quando nem todos tem as mesmas condições para o acesso à educação.

Palavras-chave: Educação; Desigualdade Social; Coronavírus.

\section{ABSTRACT}

Education in times of pandemic, it is clear that there are countless questions about the direction the world will take. The area of health, economics, as well as education is already being impacted. Therefore, the main objective of this article is to engage in a discussion about the challenges of Brazilian education in times of pandemic, presenting the marks of inequality since its genesis, as well as its impacts on the current Brazilian situation. The qualitative approach was used. Regarding the characterization of the study in terms of objectives, exploratory, explanatory and descriptive research was used. Regarding the procedures, bibliographic research was applied. It was found through this study that education is the result of social inequality, since it is intrinsically related to the emergence of the country itself, which in turn comes from an eminently unequal context. It is concluded, therefore, that Brazilian education has very intense marks of its historical past that are reflected up to the present day, showing its content still segregationist and reinforcing inequality. With the coronavirus pandemic, this character is even more visible when not everyone has the same conditions for access to education.

Keyword: Education; Social Inequality; Coronavirus. 


\section{INTRODUÇÃO}

Identificado a primeira vez na China em Wuhan, o novo coronavírus denominado SARS-CoV-2, causador da doença COVID-19 espalhou-se pelo mundo entre o final de 2019 e início de 2020, tomando proporções tão drásticas que se tornou correto denomina-lo, no 11 de março de pandemia (LANA et al, 2020). Conforme o Ministério da Saúde o coronavírus apresenta um quadro clínico que varia entre infecções assintomáticas a quadros respiratórios graves. As formas de transmissão são tosse, aperto de mão, espirro, objetos contaminados, entre outros.

Em meio a COVID-19 ações governamentais tornam-se necessárias. Medidas como o isolamento social, o fechamento temporário de inúmeras instituições, sobretudo de ensino são fundamentais no combate a esse vírus, ainda considerado um enigma para cientistas e que indispõe de uma vacina comprovadamente eficaz. Tais ações, apesar de imprescindíveis colocam em evidência outras problemáticas, como por exemplo, a disparidade no acesso à educação. Sendo assim, o objetivo deste artigo é dissertar sobre os desafios da educação em tempos de pandemia abordando a desigualdade e seus reflexos no eixo educacional, bem como apresentar os impactos do coronavírus enquanto agravante para às discrepâncias na área educacional.

Em virtude do cumprimento de medidas para contermos o surto da pandemia, algumas escolas adotaram as aulas fornecidas de forma virtual ou online, apesar de nem todos disporem dos meios necessários. A priori, a realização do ENEM também terá a opção virtual e por enquanto apenas medidas paliativas estão sendo tomadas acerca de quais os rumos que está irá dispor no contexto atual, já que nem todas as escolas estão aptas a realizar a prova "online". E apesar de ainda que tardia a decisão de adiamento das provas tenha sido confirmada, milhares de alunos encontram-se "desamparados", visto que indispõe de um conjunto de aparatos para continuar a estudar em suas residências. A Covid torna-se um intensificador da desigualdade na medida em que impossibilita que todos os alunos tenham acesso à educação à distância por indisporem de acesso à internet, a notebooks ou computadores. Levanta, ainda de forma mais assustadora como se encontra precarizada a educação, e como é discrepante o acesso à esta.

Para a sua realização utilizou -se a abordagem qualitativa. Quanto a caracterização do estudo quanto aos objetivos temos as pesquisas exploratória, visto que apesar do contexto educacional tratar-se de uma temática que existe muito conhecimento estruturado, o fator "pandemia do coronavírus" traz um caráter inovador e pouco explorado. A pesquisa explicativa foi utilizada com o intuito de apresentar possíveis fatores que determinam ou podem contribuir para a persistência da desigualdade educacional brasileira e o viés descritivo, no intuito de apresentar as características da gênese da educação brasileira e suas particularidades, bem como suas problemáticas até os dias atuais, sobretudo em tempos de pandemia. Utilizou-se enquanto procedimento a pesquisa bibliográfica a fim de buscar relações entre diversos conceitos no que concerne à educação.

Sendo assim, torna-se essencial compreender o viés substancialmente destoante e segregacionista que a educação brasileira sempre apresentou e como este vem se fomentando na conjuntura atual. Se faz necessário, portanto criticidade por partes da sociedade civil organizada ao avaliar posturas políticas e um policiamento constante de suas práticas a fim de evitarmos violação dos nossos direitos.

\section{EDUCAÇÃO NO BRASIL E OS TRAÇOS HISTÓRICOS DA DESIGUALDADE}

Os primeiros indícios de "educação" no Brasil surgem no período colonial, sob supervisão dos jesuítas vindos de Portugal, a qual apresentam a missão de catequizar os índios. As escolas jesuítas eram regulamentadas pelo documento "Ratio Studiorum", criado por Inácio de Loiola. Por se tratar de uma imposição e não de uma troca real entre culturas, para os índios, resultou no esfacelamento abrupto de sua cultura.

Em conformidade com Romaneli (1986) a atividade escolar foi sinônimo no período colonial de sustentáculo para impor e preservar a cultura transplantada. A forma como foi gestada a colonização brasileira, a estratificação social, o controle político, aliado ao uso de modelos importados de cultura consideradas "desenvolvidas" tornaram possíveis a evolução da educação escolar brasileira.

Nesse sentido, a função da escola foi a mantenedora dos privilégios de classe ao se utilizar de mecanismos de seleção escolar e de um conteúdo cultural incapaz de propiciar as diversas camadas sociais sequer uma preparação eficaz para o trabalho. Igualmente, afirma que a necessidade de "manter os desníveis sociais caracterizou a educação como um instrumento de reforço as desigualdades" (ROMANELI, 1986, p. 24).

Seco et al., (2020) afirma que no intuito de promover o povoamento estratégico, o marques de pombal alimentado por ideias iluministas expulsa os jesuítas tirando o comando das mãos destes para o comando do Estado. A qual ocasionou uma desestabilização do sistema educacional, visto que não propiciou a implementação de um novo modelo em sua substituição.

Com a chegada da família portuguesa em 1808 , 
fugida da Europa devido a invasão napoleônica, desembarca no Rio de Janeiro, a família real. Esta, trouxe consigo mais de 60 mil livros que posteriormente daria origem a Biblioteca Nacional, na própria capital carioca (GOMES, 2007). A fim de atender os interesses da própria coroa e aristocracia brasileira acabou-se por investir na educação brasileira, culminando na criação das primeiras escolas de ensino superior de medicina em Salvador (Bahia) e no Rio de janeiro.

Com a Constituição de 1824 poucos indícios no quesito educacional foram apresentados, visto que era quase imperceptível a presença do Estado, visto que tratava-se ainda de uma sociedade escravista, autoritária e que privilegiava a minoria. Segundo Romaneli et al., (1986) não houveram construções de escolas, contratação de professores com espaços físicos adequados, métodos didáticos aprofundados, muito menos a inclusão da classe popular do país, visto que manteve a descentralização da educação básica. Sendo assim, apenas os filhos de famílias ricas tinham acesso facilitado ao colégio e poderia cursa em universidades em Portugal.

Com a Constituição da Republica de 1891 é instituído o sistema federativo de governo e consagrado a descentralização do ensino no Brasil. Refletia a dualidade de ensino, a qual se via as escolas secundárias, acadêmicas e superiores para a classe dominante e as escolas primárias e profissionais para as classes menos abastadas (ROMANELI, 1986).

Romaneli (1986), ressalta que com o Federalismo e a autonomia econômica e educacional, agora voltada para os Estados, alavancou-se ainda mais as desigualdades estaduais, visto que os Estados que comandavam a política e economia da nação, sede do poder econômico estavam em condições privilegiadas para desenvolver-se, já que dispunham de melhores recursos, aparelho educacional, enquanto os Estados mais pobres, sem nenhuma experiencia e sem nenhum aporte, ficara a mercê da própria sorte. Sendo assim, caracterizou-se por ampliar as desigualdades socioeconômicas e culturais em diversas regiões do país, impossibilitando uma unificação e permanência de atividades pedagógica.

Com a entrada da década de 30 , com o governo de Getúlio Vargas passos importantes são dados em prol da educação. O Ministério da Educação e secretarias dos estados foram criados por meio do Decreto $n^{\circ} 19.850$, de 11 de abril de 1931, a ideia de educação pública, obrigatória, gratuita e laica começa a ser disseminada (BRASIL, 1931).

A partir de 1935 discussões acerca do sistema educacional brasileiro se evidenciam com o movimento da Escola Nova, que defendiam a educação igualitária sob o viés estatal e o ensino católico, voltado ao ensino religioso. Gustavo Copanema, adepto do movimento escolanovista evidenciava ser a educação um dos principais instrumentos do Estado, ou seja, por meio dele ideologias morais, políticas e econômicas poderiam ser moldadas e disseminadas em conformidade com o Estado Novo. Iniciativas como a reforma do ensino secundário em 1942, a reforma universitária, a criação do sistema universitário público federal, o INEP, a criação do SENAI em 1942, Faculdade Nacional de Filosofia da Universidade do Brasil, entre outros, foram medidas essenciais para a educação brasileira, apesar de ainda ser considerado exorbitante a taxa de analfabetismo, ainda superior a $50 \%$ (FONSECA, BOMENY, 2020).

A partir de 1950 com o projeto de Juscelino Kubitschek de desenvolver cinquenta anos em cinco com o apoio do capital estrangeiro, às ações na área da educação se voltam para o ensino técnico profissional, deixando a cargo das faculdades aqueles que tinham "vocação intelectual". "O espírito do desenvolvimentismo inverteu o papel do ensino público, colocando a escola sob os desígnios diretos do mercado de trabalho" (GHIRALDELLI, 2001, p. 95).

$\mathrm{Na}$ década de sessenta as ideias de Paulo Freire começam a emergir, pois "nascem como uma das expressões da emergência política das classes populares e a uma prática dirigida sobre o movimento popular." (FREIRE, 1967, p. 3). Inclusive sua pedagogia encontra como adepto o João Goulart que defendia a reforma de base a fim de superar o analfabetismo no Brasil. Este evidenciava um Plano Nacional de Educação a fim de superar gradualmente o analfabetismo no Brasil. Proposta essa que não chegou a se efetivar, pois desde a sua posse conservadores o viam com "maus olhos "o considerando de esquerda e comunista, o que culminou em 31 de março de 1964 no golpe militar. Sousa et al (2018) afirma que Goulart deixou atrás de si um rastro de desorientação e desagregação e o país que continuara a ser regido pela ainda constituição de 1946, passara a ser governado por atos institucionais, ceifando a democracia.

Tais acontecimentos acabaram por ocasionar em inúmeras consequências para o sistema educacional, um quadro de carências, desqualificação profissional e salarial. Nesse período os governos implementaram ações como o MOBRAL - Movimento Brasileiro de Alfabetização, por meio da Lei n ${ }^{\circ}$. 5.379, de 15 dezembro de 1967 que resultou em baixos resultados, a da vinculação constitucional de recursos para a educação pela Constituição de 1967 a qual representou vários danos para a qualidade do ensino ministrado para a população. A desvalorização da formação humanista com a retirada do currículo de disciplinas como história e geografia substituídos por estudos sociais e educação moral e cívica e destaque para a educação física (TEIXEIRA, 2015).

A Constituição de 1988 trouxe para a educação algumas conquistas como: 
a consagração da educação como direito público subjetivo, o princípio da gestão democrática do ensino público, o dever do Estado de prover creche e pré-escola às crianças de 0 a 5 anos, a oferta de ensino noturno regular, o ensino fundamental e médio gratuito (inclusive para os que a ele não tiveram acesso em idade própria), o atendimento educacional especializado aos portadores de deficiências, entre outras (TRIGUEIRO, 2016, p. 57).

Após a CF 88 documentos com viés democráticos começaram a ser elaborados, entre eles, destaca-se a Lei brasileira de inclusão que inclui a educação enquanto uma de suas prioridades. A inserção do ensino da cultura afrobrasileira e africana por meio da LEI 10.639/03. A Lei $12.711 / 2012$ ou lei de cotas trata-se da reserva de $50 \%$ das vagas para alunos que tenham concluído todo o ensino médio em escola pública, em cursos regulares ou oriundos da educação de jovens e adultos. Tal porcentagem é dividida igualmente entre alunos que recebem até 1,5 salário e aqueles que recebem uma renda superior. Considerando o percentual mínimo correspondente ao da soma de pretos, pardos e indígenas no estado de acordo com o último censo do IBGE. Porém, tivemos alguns retrocessos, como a lei 13.415/2017 que altera LDB e estabeleceu uma mudança na estrutura do ensino médio ampliando a quantidade de horas de 800 horas para 1000 horas anuais (até 2022) e definindo uma nova organização curricular, mais flexível e que contemple uma Base Nacional Curricular e os itinerários informativos, com foco nas áreas de conhecimento e na formação técnica profissional. (MEC, 2018). Dispositivo esse que foi elaborado e discutido por uma minoria, enquanto os principais interessados (professores, estudantes, coordenadores) foram excluídos do processo discussão e elaboração.

\section{A EDUCAÇÃO BRASILEIRA E SUAS PARTICULARIDADES}

Conforme afirma Jessé de Souza em sua obra " A elite do atraso", a elite brasileira, ao contrário das elites de outros países, vislumbra apenas colher os frutos da exploração desmedida do capital, muitas vezes não se importando nem mesmo com a manutenção de táticas para se manter no sistema vigente, a sua autorreprodução. $\mathrm{Ou}$ seja, a "elite do atraso" trata-se de característica eminentemente brasileira a qual estas realizam ações contrarias ao bem estar social da sociedade. (SOUZA, 2017)

Ao analisar a gênese do Brasil constata-se que esta é fruto da escravidão, do extermínio de inúmeras tribos indígenas, da subtração de suas matérias primas, da sua condição de colônia, de sua submissão aos povos já considerados "desenvolvidos". Tais fatos constituem em inúmeros reflexos para a sociedade brasileira, sobretudo no que concerne à educação.

Um dia pontuou Florestan Fernandes em seu livro o "Dilema educacional brasileiro"

Poucos países, no mundo moderno, possuem problemas educacionais tão graves quanto o Brasil.Com herança do antigo sistema escravocrata e senhorial, recebemos uma situação dependente inalterável na economia mundial, instituições políticas fundadas na dominação patrimonialista e concepções de liderança que convertiam a educação sistemática em símbolo social dos privilégios e do poder dos membros e das camadas dominantes (FERNANDES, 1976, p. 192).

O SAEB foi a primeira iniciativa nacional de avaliação da educação básica criada em 1990, que se trata de um conjunto de avaliações externas aplicadas a cada dois anos, na rede pública e privada. Permite ao INEP realizar um diagnóstico da educação básica brasileira e identificar fatores que podem interferir no desempenho do estudante explicando seus resultados por meio de informações contextuais (INEP, 2020, p.1).

Em 2005 foi criada a Avaliação Nacional do Rendimento Escolar pelo Ministério da Educação, mais conhecida como "Prova Brasil" que é composta por testes de matemática e língua portuguesa e são aplicados para alunos da $5^{\circ}$ ao $9^{\circ}$. Atualmente passou a ser realizada em conjunto como Saeb. Já em 2007 foi criado o IDEB Índice de desenvolvimento da educação básica, a fim de avaliar a qualidade da educação básica brasileira por meio de dois conceitos: o fluxo escolar e as médias de desempenho nas avaliações, a qual se utiliza do censo escolar e SAEB (INEP, 2020).

Segundo o IDEB de 2017 a rede pública atingiu 5,5 , já a rede privada que participa com $18 \%$ das matriculas nos anos iniciais do ensino fundamental apresentam um IDEB 1,6 superior ao observado na escola pública. Apesar da rede privada não ter alcançado a meta proposta para 2017, em 15 unidades da federação esta obteve um resultado igual ou superior a 7 e 16 atingiram a meta (INEP, 2017).

Ao analisar os resultados do IDEB 2017 percebese uma considerável discrepância regional no que concerne à educação. Enquanto 138 municípios do Nordeste atingiram 3,7 no ideb, apenas 1 município do Sudeste atingiu essa pontuação. Dos que atingiram resultados entre 3,8 a 4,9, 1063 municípios eram do Nordeste e apenas 45 da região Sudeste. Enquanto que de 5 á 5,9,420 eram do Nordeste e 389 do Sudeste. Já no que se refere a pontuações maiores, continham apenas 153 municípios do Nordeste, enquanto havia a presença de 


\subsection{2 municípios do Sudeste (INEP, 2017).}

De fato, são imensuráveis os reflexos da formação brasileira até os dias atuais. Apesar de já se passado mais de três séculos, a educação brasileira ainda é considerada uma das piores do mundo. Segundo o PISA- Programa Internacional de Avaliação de Alunos de 2018, a qual possui o intuito de avaliar a qualidade educacional dos países participantes, publicado em 2019, afirma que o Brasil ocupa hoje, nas três áreas avaliadas, leitura, matemática e ciências, um dos piores rendimentos educacionais, entre os 79 países participantes. "A qual $68,1 \%$ "dos estudantes brasileiros, com 15 anos de idade, não possuem nível básico de matemática, o mínimo para o exercício pleno da cidadania. Em ciências, o número chega a $55 \%$ e, em leitura, 50\%. Os índices estão estagnados desde 2009" (INEP, 2019, p. 1).

O ENEM - Exame Nacional do Ensino Médio foi criado em 1998 e tem o intuito de avaliar os desempenhos do estudante após a conclusão da educação básica. No que concerne ao seu conteúdo trata-se de uma avaliação que contempla ciências da natureza, linguagens e códigos e ciências humanas, matemática e suas tecnologias e redação. Apenas a partir 2009 medidas governamentais passaram a estimular o ENEM como um meio para a inserção no ensino superior (BRASIL, MEC,1998).

Demonstra uma pretensão em efetivar uma reforma educacional, visto que não se pretende identificar apenas uma elevação nas estatísticas de indicadores educacionais, mas a constatação do seu real desempenho e assim traçar novas políticas no âmbito educacional. Mas atua igualmente a fim de "cumprir o papel de formar este novo indivíduo para este novo mundo do trabalho" (ANDRIOLA, 2011, p.107).

Além disso, nos últimos anos, tem havido um deslocamento do investimento do empresariado privado do ensino médio para o ensino superior, o que tem levado a uma publicização da educação básica e uma privatização da educação superior. Os alunos que cursaram o ensino médio na escola privada buscam a educação superior nas instituições públicas; aos que cursaram o ensino médio na escola pública sobra apenas a opção das instituições privadas. Em contrapartida, os resultados nos sistemas de avaliação mostram que, na educação básica, a escola privada tem se mostrado superior em qualidade à escola pública, enquanto que, no ensino superior, a situação se inverte (TRIGUEIRO, 2016, p. 59).

Em consonância com o INEP, após a avaliação do ENADE 2018, um dos principais pilares do SINAES Sistema Nacional de Avaliação de Educação Superior, com o intuito de avaliar o desempenho dos estudantes ingressantes e concluintes em relação aos conhecimentos apresentados ao longo do curso, constatou -se que "apenas
5,8\% dos cursos atingiram nota máxima. Apenas 3,3\% das faculdades privadas atingiram nota 5 , na rede pública apenas $20 \%$, enquanto isso mais de 300 instituições ficaram sem conceito de avaliação" (INEP, 2019, p. 1).

Apesar de crescentes os investimentos na área da educação superior, pouco se sabe sobre os seus desempenhos. Os resultados do ENADE- Exame Nacional de Desempenho dos Estudantes vislumbram a combinação de várias informações para chegar a um número que irá conceituar os cursos. Além do Enade existe a avaliação institucional e a avaliação dos cursos de graduação, essa avaliação pode variar entre 1 e 5 . Para as instituições com menos de 3, o MEC envia avaliadores munidos de questionários detalhados que produzem informações sobre se as instituições e cursos podem ou não ser autorizados a funcionar (IBIDEM, 2019).

Conforme Schwartzman (2018) a OECD Organização para a Cooperação e Desenvolvimento Econômico constatou que as provas do ENADE evidenciam um conjunto de problemáticas no que se refere a avaliação, visto que indispõe de padronização, avaliar o aumento ou redução do desempenho de um ano para outro e contrapor a qualidade de diferentes cursos. Nessa metodologia de investigação não se evidencia claramente se trata-se de um resultado bom, ruim ou ótimo o desempenho do ensino superior.

Trata-se de uma prova a qual os alunos não possuem interesse, já que não impactam a sua vida acadêmica. Outrossim, refere-se a indicações que não são apresentadas como a taxa de inserção no mercado de trabalho após a conclusão do curso ou a taxa de evasão dos cursos. Dados como titulação dos professores, nota do ENEM, avaliação infraestrutura das faculdades tirar o foco do que realmente é essencial, a avaliação dos estudantes, misturam coisas divergentes e acabam por desfavorecer os cursos de formação profissional. No que concerne a avaliação realizada pela CAPES constatou-se pela OECD que o intuito principal do sistema avaliativo perdeu espaço para uma preocupação em avaliar os professores. Inexiste uma preocupação com o destino profissional dos estudantes ou sobre a natureza especifica dos programas de mestrado (SCHWARTZMAN, 2018).

Ademais, com a constante inserção do ensino superior por meio do ensino EAD nas últimas décadas, acabou por ocasionar em uma expansão no acesso à educação superior, resultado direto de políticas estatais. Tal fato, alimenta o setor privado mercantil, fortalecendo o mercado para o capital, além de ampliar as estatísticas educacionais do acesso de camadas da população ao ensino superior. No entanto, questiona-se a real qualidade na formação dos estudantes, no que concerne a métodos avaliativos eficazes, na realização dos estágios supervisionados, na formação geral do estudante, visto que impossibilita a vivência acadêmica (CFESS, 2014). 
Sem tais dados torna-se complexo analisar a real efetividade do ensino superior no Brasil. Apesar de ser notório uma maior inserção de alunos no ensino superior público ou privado por meio de programas como o FIES e o PROUNI e até mesmo o ensino EAD. Só a constatação quantitava é ineficaz para atingirmos um ensino superior de qualidade. Torna-se necessário novas ferramentas que definam com maior clareza a real situação do ensino superior brasileiro, para assim podermos traçar novas propostas á essa temática.

\section{CORONAVIRUS $X \quad$ EDUCAÇÃO: CONSIDERAÇÕES SOBRE OS IMPACTOS NA REALIDADE BRASILEIRA}

Inesperadamente "o mundo mudou", acordamos e passamos a vivenciar uma nova realidade. Com o surgimento da Covid -19 doença ainda desconhecida em termos mundiais, inúmeras problemáticas entraram em "xeque", como impedir que a economia sofra muitos danos? Realizar ou não o isolamento social? Afinal, como lidar com um vírus a qual pouco se sabe sobre ele? Liberar ou não às escolas, faculdades e setores afins e qual o impacto na área da educação?

Inúmeros são os questionamentos e poucas ainda são as respostas, no entanto no que concerne à educação, já se percebem os impactos. Em um país, sinônimo de precariedade educacional e um dos portadores do pior rendimento educacional do mundo, o Brasil caminha hoje para o "algar".

Conforme (TRIGUEIRO, 2016, p.57) a LDB atual defende

a formação do indivíduo, de 0 ano de idade até o final do ensino médio, sendo dividida em três etapas consecutivas: a educação infantil, o ensino fundamental e o ensino médio. A oferta dos dois primeiros é de responsabilidade dos municípios; a do último, dos estados. Essa ampliação tem se refletido na integração entre seus vários níveis e destes com o ensino superior, que é de responsabilidade da União. Outra garantia trazida por esta lei é a oferta gratuita de educação básica aos que não tiveram acesso a ela na idade própria, bem como aos alunos com deficiência ou superdotados, mediante atendimento especializado gratuito, preferencialmente na escola pública.

Apesar de tais conquistas ainda se trata de um sistema educacional precarizado. O Brasil carrega consigo o fardo de ser um dos países mais desiguais do mundo, ocupando a $7^{\circ}$ posição no ranking, segundo o PNUD Programa Nações Unidas para o Desenvolvimento. Sendo assim, em tempos de pandemia, a qual estamos vivenciando atualmente impossibilita que todos os alunos, ou a maioria deles tenham acesso, por exemplo, ao ensino á distancia, enquanto se define quais rumos iremos tomar (PNUD, 2019).

Uma das ferramentas de avaliação para ingressantes ao ensino superior no Brasil trata-se do ENEM - Exame Nacional do Ensino Médio, uma das mais esperadas, pois traz a possibilidade não apenas da inserção no mercado de trabalho, mas para muitos, de uma mudança de realidade, de vida. É no ENEM que muitos buscam a chance de ter um futuro melhor, mesmo em meio as inúmeras dificuldades diárias, seja para chegar até a escola, para permanecer nela, para ter aula de qualidade, estrutura adequada nas escolas, entre outras.

Apesar de a priori, a decisão pelo Ministério da educação tenha sido de não adiar as provas do Enem, percebeu-se por meio da intervenção do Ministério Público questionando a comprovação ao acesso igualitário nas condições de estudos, bem como uma enorme reação por parte da sociedade civil e mais recentemente o projeto de adiamento aprovado no senado que seria inevitável não adiar às provas, visto que seria extremamente prejudicial para contornamos a situação da pandemia. Enquanto, deixar a mercê um enorme contingente de alunos que por impossibilidade financeira de ter acesso a prepara-se para a prova, tratar-se-ia de uma enorme violação ao direito ao acesso à educação contido no artigo seis da carta magna do país (MEC, 2020).

Em meio ao "boom" do Coronavírus no Brasil evidencia-se uma grave crise política que é simultânea a uma crise econômica, mas que implica igualmente em dimensões jurídicas, visto que a democracia defendida na constituição de 1988 encontra-se ameaçada. Societais, visto que promove constantes conflitos nas relações interpessoais em parcelas da população, bem como culturais dado que jogos de forças tem ocasionado em choques de identidade, valores e comportamentos (ALMEIDA, 2018).

Se o ENEM não foi feito para corrigir injustiças este muito menos deve aprofunda-las. $\mathrm{O}$ seu intuito é o ingresso no ensino superior e a possibilidade de entrada no mercado de trabalho. Conforme artigo seis da CF 88 a educação é um direito social fundamental e, portanto, inerente a todos os cidadãos. Negar o acesso a inúmeros estudantes a realização dessa avaliação, significa negar o direito pleno a educação, pois impede que estes tenham acesso pelo menos a concorrer a vaga ao ensino superior, "partindo do mesmo ponto de partida" (BRASIL, 2016).

Além disso, outros pontos merecem destaque, pois incontáveis alunos já se encontram em desvantagem. Devido a inviabilidade financeira, indispõe do acesso a rede de internet ou mesmo computador, notebooks para acompanhar aulas à distância por meio do cursinho online. Outros nem mesmo chegaram ter aulas ou a receber os 
livros escolares. Sendo assim, torna-se dificultado à sua preparação para o ingresso ao ensino superior. No Brasil os únicos estudantes que possuem o privilégio de ter acesso a aula online são os alunos da rede particular, pois a rede pública até o presente momento indispõe de uma ação efetiva para fornecer os recursos necessários e lançar medidas para superar ou amenizar a impossibilidade das aulas presenciais, sobretudo no que concerne aos municípios. $\mathrm{O}$ abismo entre escolas públicas e privadas nunca foi uma novidade no Brasil, porém em tempos de crise ela se mostra ainda mais presente, visto que ao contrário de muitas escolas públicas, escolas privadas desfrutam de estrutura material, tecnológica e financeira que permite propiciar aos seus alunos a assistência educacional necessária. Tal fato se mostra evidente quando os resultados do Relatório pedagógico de 2011 e 2012 demonstram que os resultados dos alunos que estudaram somente ou a maior parte em escolas particulares obtiveram notas substancialmente maiores em todas as áreas do conhecimento no ENEM e que os índices de abstenção de dos alunos, cujas famílias recebiam até um salário mínimo ou entre 1 e 1,5 salário são significativamente maiores (INEP, 2015).

Segundo a pesquisa sobre Tecnologias de Informação e Comunicação nos domicílios brasileiros de 2018, apenas $70 \%$ da população tem acesso à internet, sendo assim $30 \%$ indispõe de tais recursos, o que configura aproximadamente 60 milhões de pessoas. Quando propostas desse tipo são apoiadas refletem em pessoas que por não ter acesso aos recursos midiáticos acessíveis, não tem voz e vez, são para o Estado apenas mais um número na estatística (IBGE, 2018).

De fato, não podemos desconsiderar a possibilidade do ensino remoto, visto que se torna fora de cogitação a liberação das aulas presenciais em meio a pandemia. Porém, questiona- se quais as ações irão ser tomadas para aqueles que indispõe do acesso a tais recursos, possam ainda que de modos divergentes ter acesso à educação. "Uma estratégia consistente para o ensino remoto é aquela que busca mitigar as condições heterogêneas de acesso e os diferentes efeitos de soluções a distância em função do desempenho prévio dos estudantes." (TODOS PELA EDUCAÇÃO, 2020, p.9) Sendo assim, o primeiro passo seria identificar os recursos tecnológicos que já estão ao alcance dos alunos ou que podem ser rapidamente disponibilizados e tornar menos rígidos o acesso à internet para evitar penalizar aqueles que se encontram em situações mais vulneráveis.

Ressalta igualmente que estão entre os equipamentos de tecnologia da informação e comunicação mais acessíveis a população brasileira o telefone celular a qual está presente em $93 \%$ dos domicílios, a televisão em $96 \%$ e o computador em apenas $42 \%$. Tais propostas devem ser lançadas levando em consideração a maior acessibilidade possível, sendo assim, analisar os recursos disponíveis torna-se essencial (IDEM, 2020).

$\mathrm{O}$ envolvimento de gestores escolares e professores devem ser estimulados, principalmente, porque a educação virtual ainda é bem recente na cultura brasileira e seu engajamento trará alguns impasses que só poderão ser resolvidos com muito dialogo e compreensão da realidade da educação brasileira. Torna-se primordial o aprimoramento profissional dos professores e o seu nível de formação para trabalhar com os recursos tecnológicos, já que conforme Todos Pela Educação (2020, p.13) “cerca de $67 \%$ apontaram necessidade de aperfeiçoamento" nesse quesito.

Em uma sociedade eminentemente capitalista com viés Neoliberal, entendemos que todos os assuntos são tratados com muita objetividade e superficialidade, a fim de atingir o "status quo" propício a disseminação de valores e ideias do capital. Por isso, faz-se necessário o nosso policiamento diário para ações que comprometam o direito de todos.

\section{CONSIDERAÇÕES FINAIS}

Em meio aos fatos mencionados compreende-se, portanto, que são inegáveis as marcas da desigualdade social no processo de gênese da educação, afinal, estão intrinsecamente relacionadas, pois a própria constituição do país se deu em meio a exploração desmedida dos povos negros e indígenas. A educação é pensada no Brasil a princípio para disseminar os ideais da Igreja Católica que vinha perdendo adeptos. Posteriormente, para atender as demandas da corte portuguesa que desembarcara no Brasil e a aristocracia.

A educação brasileira desde os seus primórdios sempre foi sinônimo de privilégio para a minoria mais abastada, uma "elite do atraso" que possui enquanto interesse "inalterável" a exploração desmedida do capital, que deixa aquém o bem-estar social. Tal fato acaba se refletindo até os dias atuais, já que nem todos tem o mesmo acesso à educação e o alcance maior ainda se encontra nas mãos da elite. Enfim, trata-se apenas de uma nova roupagem do que acontecera a três séculos atrás. E o que se percebe é que em tempos de crise essa disparidade se intensifica e a deixa ainda mais evidente, como a que estamos presenciando em decorrência da COVID-19.

Apesar da garantia da gratuidade do ensino público e a igualdade de condições de acesso à educação pela LDB, assegura a abertura para coexistência de ensino público e privado, e com isso o Estado se esvai das suas responsabilidades e mais uma vez a população paga por um direito de que é garantido por lei de forma gratuita. Essa forma de ensino pode provocar disparidades no que se refere a formação educacional da população, pois aqueles que tem condições de acessar o ensino privado 
consequentemente terão maiores e melhores condições de aprendizagem, uma vez que o ensino público na nossa sociedade mostra-se cada vez mais sucateado, tanto no que se refere a questões estruturais e de acesso quanto no que diz respeito a qualificação e valorização dos profissionais.

Em meio a uma pandemia mundial do coronavírus, além do complexo problema de saúde pública e como reflexo em virtude do isolamento social, na economia, o país igualmente enfrenta uma crise política com desdobramentos ainda maiores que afetam a sociabilidade, a democracia, a cultura e o bem estar social. Em meio a essa enorme problemática, debates sobre a educação e como amenizar os impactos da desigualdade social mostra-se necessários. Sendo assim, constatou-se que com base nos dados do IBGE, INEP e TODOS PELA EDUCAÇÃO que a disparidade social ainda torna o Brasil um dos países mais desiguais do mundo. E com base no PISA 2018, com quase 70\% dos alunos com até 15 anos sem os conhecimentos básicos de matemática, português e ciências. Com uma avaliação inconsistente para os concluintes do ensino superior, que impossibilita constatala como boa ou ruim. E como demostrou os dados do IDEB 2017 com uma profunda divergência regional no que concerne aos resultados obtidos entre a região sudeste e nordeste, por exemplo. Assim como ainda se percebe uma distância considerável entre os resultados obtidos pelas escolas públicas e privadas.
Sendo assim, faz-se necessário traçar medidas de ampliação do acesso a rede de internet para as populações mais carentes que já possui acesso a computador, notebook, tablet e apresentar a modalidade "online" como uma opção, diversificando as experiencias de aprendizagem. No entanto, oferecendo o suporte necessário para aqueles que indispõe de tais meios, com a entrega de materiais didáticos e orientações aos pais.

A competência dos professores será a de propiciar uma experiencia enriquecedora para os estudantes, ainda que forma remota. O diálogo entre professores e gestores torna-se essencial para superar os impasses promovidos pela recente cultura da "educação à distância". A qual deve-se compreender como um "complemento" e não como "base" para a educação brasileira.

Conclui-se, portanto, que a educação brasileira sempre apresentou traços de desigualdade, porém com a COVID-19 a intensifica, tornando-se necessário, ainda de forma mais rigorosa, discussões sobre tal temática, a fim de traçar medidas que possibilitem o acesso pleno a todos os estudantes a uma educação de qualidade. Compreendese igualmente a urgência de adotarmos uma postura mais policialesca para com os nossos representantes, para que possamos agir e reagir de forma crítica a possíveis violações de direitos.

\section{REFERÊNCIAS}

ALMEIDA, Mário de Souza. Elaboração de projetos de TCC, dissertação e tese: uma abordagem simples, prática e objetiva/Mario de Souza Almeida-2. ed.- [3. Reimpr.] -São Paulo:Atlas,2017.

ANDRIOLA, W. B. Doze motivos favoráveis à adoção do Exame Nacional do Ensino Médio (ENEM) pelas instituições de Ensino Superior (IFES). Ensaio: Avaliação e Políticas Públicas em Educação, Rio de Janeiro, v. 19, n. 70, p. 107-120, jan./mar. 2011. Disponível

em: http://www.scielo.br/pdf/ensaio/v19n70/v19n70a07.pdf. Acesso em: 07/07/20

BOMENY, Helena. E ele voltou... o segundo governo Vargas > A educação no segundo governoVargas.Disponível:https://cpdoc.fgv.br/producao/ dossies/AEraVargas2/artigos/EleVoltou/Educacao\#top.

Acesso em 18/05/2020.

BRASIL. Constituição da República Federativa do Brasil. Disponível https://www2.senado.leg.br/bdsf/bitstream/handle/id/518 231/CF88_Livro_EC91_2016.pdf> Acesso em: $28 / 05 / 2020$

BRASIL. Ministério da Educação. Instituto Nacional de Estudos e Pesquisas Educacionais Anísio Teixeira - INEP. Portaria MEC n ${ }^{\circ}$ 109, de 27 de maio de 2009. Estabelece a sistemática para a realização do Exame Nacional do Ensino Médio no exercício de 2009. Disponível em: http://download.inep.gov.br/educacao_basica/enem/1 egislacao/2009/portaria_enem_2009_1.pdf. Acesso em: 08/07/2020.

BRASIL, Decreto $\mathbf{n}^{\circ} \mathbf{1 9 . 8 5 0}$, de 11 de abril de 1931 . Disponível

https://www2.camara.leg.br/legin/fed/decret/19301939/decreto-19850-11-abril-1931-515692republicacao-82984-pe.html. Acesso em :18/05/2020.

FERNANDES, Florestan. O Dilema da educação brasileira. Disponível em < https://www.passeidireto.com/arquivo/37818160/floresta 
n-fernandes-o-dilema-educacional-brasileiro> Acesso em : 19/05/2020.p.192-219.

FONSECA, Bianca Trindade. REFLEXÕES ACERCA DA EDUCAÇÃO DURANTE A DITADURA MILITAR BRASILEIRA (1964-1985).Disponível em :https://monografias.brasilescola.uol.com.br/educacao/ref lexoes-acerca-educacao-durante-ditadura-militar.htm.

Acesso em 18/05/2020.

FREIRE, Paulo. A educação como prática da liberdade. $23^{\mathrm{a}}$ ed. Rio de Janeiro: Paz e Terra, 1. ed, 1967.

GHIRALDELLI, Paulo. Introdução à Educação Escolar Brasileira: História, Política e Filosofia da Educação. Disponível em

http://www.miniweb.com.br/educadores/artigos/pdf/intro du-edu-bra.pdf>Acesso em:18/05/2020.

GOMES, Laurentino. 1808: História do Brasil / Laurentino Gomes - 1956. Planeta do Brasil,2007.

INEP. Pisa 2018 revela baixo desempenho escolar em leitura, matemática e ciências no Brasil. Disponível em $:<$ http://portal.inep.gov.br/artigo//asset_publisher/B4AQV9zFY7Bv/content/pisa-2018revela-baixo-desempenho-escolar-em-leituramatematica-e-ciencias-no-brasil/21206> Acesso em 19/05/2020.

INEP-Inep divulga resultado do Enade 2018; apenas $\mathbf{5 , 8 \%}$ dos cursos atingiram a nota máxima. Disponível em https://querobolsa.com.br/revista/inep-divulgaresultado-do-enade-2018-apenas-5-8-dos-cursosatingiram-a-nota-maxima. Acesso em: 19/05/2020.

INEP - $\quad$ Resultados. Disponível em <http://portal.inep.gov.br/web/guest/relatorios. Acesso em 28/05/2020.

INEP, Ministério da Educação. Relatórios pedagógicos. Disponível em :http://portal.inep.gov.br/relatoriospedagogicos. Acesso em: 09/07/2020.

LANA, Raquel Martins; COELHO, Flávio Codeço; GOMES, Marcelo Ferreira da Costa; CRUZ, Oswaldo Gonçalves;

BASTOS, Leonardo Soares; VILLELA, Daniel Antunes Maciel; CODEÇO, Cláudia Torres. Emergência do novo coronavírus (SARS-CoV-2) e o papel de uma vigilância nacional em saúde oportuna e efetiva. Cad. Saúde Pública, v.20, n. 3, 2020 .
ROMANELLI, Otaíza O. História da Educação no Brasil (1930-1973). Petrópolis: Vozes, 1986.

SCHWARTZMAN, Simon. A qualidade da educação superior brasileira Disponível em <http://www.schwartzman.org.br/sitesimon/?p=6198> Acesso em : 19/05/2020.

TIC DOMICILIOS. Pesquisa sobre o uso das tecnologias de informação e comunicação nos domicílios brasileiros: TIC domicílios 2018. Disponível em<https://www.cetic.br/media/docs/publicacoes/2/1222 5320191028-tic_dom_2018_livro_eletronico.pdf $\geq$. Acesso em: 22/05/2020.

SOUSA, Francisco Helder Ferreira de.AI -5: CINQUENTA ANOS DEPOIS, DO GOLPE MILITAR AO ESTADO DEMOCRÁTICO DE DIREITO. Disponível em :http://revistasfap.com/ojs3/index.php/direito/article/view /180/172. Acesso em 09/07/2020.

SECO, A.P.; AMARAL, T.C.I. MARQUÊS DE POMBAL E A REFORMA EDUCACIONAL BRASILEIRA. UNICAMP Disponível em : http://www.histedbr.fe.unicamp.br/navegando/periodo_p ombalino_intro.html. Acesso em:09/07/2020

SOUZA, Jessé de. A elite do atraso: da escravidão à Lava-Jato. Leya, Rio de Janeiro: 2017.

TEIXEIRA, Albano Luiz Francisco. UM BREVE HISTÓRICO DA EDUCAÇÃO BRASILEIRA - sob o signo da precariedade. ENCONTROS - ANO 13 Número $24-1^{\circ}$ semestre de 2015. Disponível em: Acesso em: 19/05/2020.

TRIGUEIRO, E. S. O. Breve contextualização da educação brasileira. Educação em Debate, Fortaleza, ano 38, $\mathrm{n}^{\mathrm{o}} 72$ - jul./dez. 2016. Disponível em <http://www.periodicosfaced.ufc.br/index.php/educacaoe mdebate/article/view/59>.Acesso em: 09/07/2020

TODOS PELA EDUCAÇÃO. Ensino a distância na educação básica frente à pandemia da covid-19. Análise e visão do Todos Pela Educação sobre a adoção de estratégias de ensino remoto frente ao cenário de suspensão provisória das aulas presenciais. Disponível em: https://www.todospelaeducacao.org.br/. Acesso em: 22/05/2020. 